I thank Prof. B. Karlik for her interest in this work and Prof. H. Nowotny for valuable discussions. This work was supported by the Bundeskanzleramt, Verstaatlichte Unternehmungen (Section IV) of the Federal Republic of Austria.

\section{N. GeTOFF}

Institut für Radiumforschung und Kernphysik der Österreichischen Akademie der Wissenschaften,

Vienna.

${ }^{1}$ Getoff, N., Scholes, G., and Weiss, J., Tetrahedron Lett., 18, 17 (1960).

¿ Getoff, N., Z. Naturforsch., 17b, 87 (1962).

${ }^{3}$ Getoff, N., Osterr. Chem. Z., 65, 143 (1964).

4 Barrett, J., and Baxendale, J. H., Trans. Faraday Soc., 56, 37 (1960).

s Guttlbauer, F., and Getoff, N., Z. Phys. Chem., 47, 299 (1965).

${ }^{6}$ Getoff, N., $Z$. Phys. Chem. (in the press).

"Getoff, N., Osterr. Chem. Z, 63, 376 (1962).

'Rabani, J., Z. Phys. Chem. (n.f.), 66, 361 (1962).

- Nehari, S., and Rabani, J., J. Phys. Chem., 67, 1609 (1963).

${ }^{10}$ Gordon, S., Hart, E. J., Matheson, M. S., Rabani, J., and Thomas, J. K., Dise. Faraday Soc., 36, 193 (1963).

${ }^{11}$ Getoff, N., Gütlbauer, F., and Schenck, G. O., Intern. J. App. Radiat. and Isotopes, 17, 341 (1966).

\section{Analysis of the Major Constituents of Fuel Gases by Gas Chromatography}

RECENTLY, Hollis ${ }^{1}$ has reported retention data for the separation of methane, carbon dioxide, and polar materials on porous polymer beads. In these laboratories a polymeric bead column packing commercially available in the United Kingdom ${ }^{2}$ has been investigated, and has been found to have considerable advantages over conventional adsorption columns for the analysis of fuel gases which contain hydrogen, carbon monoxide, methane, carbon dioxide, and the $\mathrm{C}_{2}$-hydrocarbons as major constituents.

Hitherto the gas chromatographic analysis of fuel gas has necessitated the use of two adsorption columns. Usually a type $5 A$ or $13 X$ molecular sieve column is preferred for the separation of methane and carbon monoxide, but because this material strongly absorbs carbon dioxide, which eventually poisons it, a second column of silica gel must be used to separate this gas and the $\mathrm{C}_{2}$-hydrocarbons ${ }^{3}$. It has now been found possible using a single column to analyse a fuel gas for these components including carbon dioxide.

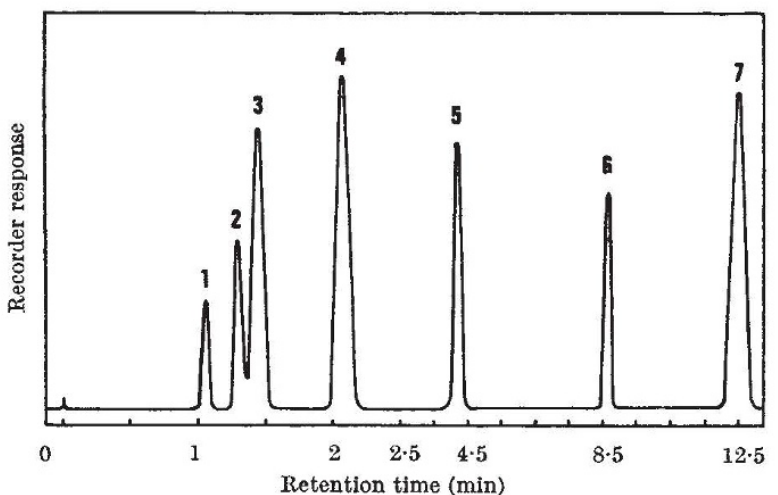

Fig. 1. Chromatogram of seven-component gas on ethylvinylbenzen polymer at $30^{\circ} \mathrm{C}$. (1) Hydrogen; (2) air; (3) carbon monoxide; (4)

The chromatogram in Fig. 1 was produced using a Perkin-Elmer model 451 gas chromatograph. A methanerich gas containing 3 per cent carbon monoxide was analysed at $30^{\circ} \mathrm{C}$ using a column $10 \mathrm{ft}$. long and $3 / 16 \mathrm{in}$. internal diameter, packed with 80-100 mesh beads of an ethylvinylbenzene polymer. This was conditioned before use by heating to $230^{\circ} \mathrm{C}$ for $\mathrm{l} \mathrm{h}$ as recommended by the manufacturer. Helium was used as carrier gas at an inlet pressure of $15 \mathrm{lb}$./in. ${ }^{2}$ gauge and a flow rate of $40 \mathrm{ml} . / \mathrm{min}$, and the components were detected using a thermistor katharometer. On this column carbon monoxide and methane were well separated, and carbon dioxide eluted within $5 \mathrm{~min}$ of injection. The column separated unsaturated $\mathrm{C}_{2}$-hydrocarbons from ethane under the same conditions.

When ethylvinylbenzene polymer was used as column packing, rapid analyses were obtained with good separation and without the 'tailing' peaks associated with other adsorption columns. In this laboratory it has enabled a gas to be analysed for seven components in 30 min with a single injection on one column, the sample size being adjusted according to the recommendations of Pauschmann ${ }^{4}$ so as to obtain a nearly linear response for hydrogen using helium as carrier gas.

R. A. Cross

The Gas Council,

Midlands Research Station,

Solihull,

Warwickshire.

${ }^{1}$ Hollis, O. I., Anal. Chem., 38, 2, 309 (1966).

2 Porapak Q., obtained from Waters Associates, Stockport, Cheshire.

3 Blakemore, G., and Hillman, G. E., Analyst, 90, 1077, 703 (1965).

- Pauschmann, H., Z. Anal. Chem., 208, 1, 16 (1964)

\section{Sensitivity to Oxygen of an Ionization Detector with Helium and Neon as the Carrier Gases}

We are interested in the analysis by chromatography of trace (v.p.m.) mixtures of oxygen in gases, and the Lovelock radioactive ionization detector ${ }^{1}$ was selected as the most appropriate for the purpose. This detector, originally developed for sensitive detection of organic compounds in a carrier stream of argon, is not very sensitive to permanent gases in argon because the metastable energy of argon $(11.6 \mathrm{eV})$ is slightly less than the ionization potentials, 12-16 $\mathrm{eV}$, of most of the permanent gases. Berry $^{2}$ suggested that helium which has a metastable energy of $19 \cdot 8 \mathrm{eV}$ would be a suitable carrier gas. We have carried out tests first with helium ${ }^{3}$ and later with neon, the metastable energy of which is $16.5 \mathrm{eV}$.

In these tests we determined the sensitivity of a Lovelock strontium-90 detector (made by W. G. Pye, Ltd., Cambridge) to helium and neon containing constant (v.p.m.) amounts of added oxygen, for different voltages applied to the detector. In each case, the flow was main. tained at $85 \mathrm{~cm}^{3}$ (N.T.P.)/min and the original carrier gas was purified to less than 0.1 v.p.m. oxygen. The sensitivity was found to increase with detector voltage up to $1,300 \mathrm{~V}$ for helium and $850 \mathrm{~V}$ for neon, above which voltages spark discharge occurred.

$\begin{array}{ccccc}\text { Carrier } & \begin{array}{c}\text { Detector } \\ \text { voltage } \\ \text { gas }\end{array} & \begin{array}{c}\text { Standing } \\ \text { current } \\ \text { (amp) }\end{array} & \begin{array}{c}\text { Sensitivity } \\ \text { amp/v.p.m. } \\ \text { oxygen }\end{array} & \begin{array}{c}\text { Noise-level } \\ \text { (amp) }\end{array} \\ \text { Helium } & 1,300 & 5 \times 10^{-9} & 3 \times 10^{-9} & 5 \times 10^{-11} \\ \text { Neon } & 850 & 5 \times 10^{-8} & 5 \times 10^{-9} & 5 \times 10^{-11}\end{array}$

Using these voltages, we determined the standing current and the noise-level for this current with carrier gas containing no added oxygen, and the change in current with added oxygen. The variation in current with added oxygen is linear up to at least 1.0 v.p.m.

The results are given in Table 1 , from which it can be seen that the minimum detectable addition of oxygen, defined as that producing a change in detector current of twice the noise level, is 0.03 v.p.m. oxygen for helium and 0.02 v.p.m. oxygen for neon.

In practice, neon with its much higher cost would scarcely be chosen in preference to helium unless there were some special reason, for example if the gases to be detected were already mixed with neon, or if a recir. culation system were used, the gases being recirculated through the purifier which is needed in any event when 